\title{
Enez Experience on the Education of Biomedical Project Design and Authorship; International Scientific Summer School, 2014
}

Around the $20^{\text {th }}$ century, medicine has perpetuated a new perspective called "evidence-based" practice. Instead of following the previous experiences, medicine is now directing its progress through evidence. Not only has the field of research but also daily practice has shifted away from individual experiences to evidence. Scientists as well as practitioners working in the field of biomedicine are now expected to have the insight of catching up with the information, which is constantly being renewed. This fast progress of field research unfortunately is not coupled with the curriculum of scientific programs in most parts of the world. Young scientists are expected to gain knowledge of creating and interpreting research studies in their fields mostly on their own. Even though most scientific societies have published guidelines and criteria for conducting research projects, research skills are not well defined. Young scientists still have a need to be enlightened by mentors, but unfortunately there's not always room for this in curricula and guidelines. However, young scientists' contributions will enable science to be enriched by new perspectives. The dynamic relationship of these two aspectsscience and young scientists-will help both of them to evolve.

The Internatinal Scientific Summer School (ISSS) was designed to improve the reflexive relationship between scientists and science. Based on the Research Practicum of Duke University, the ISSS initiative aims to improve the quality of research (1). ISSS is designed as a four-day workshop protocol with participants from different parts of research fields and also different parts of the world. From those participants with divergent backgrounds, small groups are formed. The groups are not homogenous in terms of field of interest and nationality, so the participants learn to communicate with scientists who do not belong to their own scientific societies (1-3). This important opportunity for them to hear different viewpoints brings forth listening and accommodating ideas and improves their abilities to work towards a common goal. Finding a common interest can be difficult, along with the other aspects of appropriate research studies, such as building an appropriate study design, forming the details of data collection, analysing and interpreting the data, making a feasible time line and study plan, and last but not least, preparing the research paper. In the ISS model, participants build up the research project by working in small groups. The small groups are accompanied by and have the chance to discuss their projects with faculty members during their discussions. After discussing and working on the questions of the related workshop, the groups present their study plans. Upon presentation of their work, they receive questions from the other participants and from the fac- ulty. Those questions and sometimes the feedback help them to appropriately develop a hypothesis and also to shape their research's flow chart. ISSS's non-native English speaking participants communicate in English, which enables them to practice and to develop their language skills (4). Each and every step in the four workshops requires an expertise related to different aspects of scientific research, and at the end of ISSS, participants will be equipped with these skills. ISSS provides young scientists with an opportunity for training in the research field and with project development, as well as it promotes their skills for collaboration with colleagues, their learning through experience and their English communication skills.

In 2014 , the $11^{\text {th }}$ session of ISSS was held in a small but lovely seaside area, in Enez, Turkey, in the district of Edirne. The activity was organized under the patronage of Balkan Medical Journal with the great support of Trakya University in Edirne, Turkey (Figure 1). As the weather was fine, we used an open-air meeting hall. Even though it rained occasionally, thanks to the roof, we were able to watch the rain and enjoy the fresh air all around. Participants had a chance to enjoy the sea, which they generally did just an hour before dinner. But as they were eager to work, their discussions continued even after the dinner. A little trip was organized to Edirne where the group was able to meet the rector of Trakya University and also to visit historical monuments, such as the Selimiye Mosque, the old medical faculty, and the hospital. The international faculty was formed of junior members, including Alpay Aribas (Turkey), Cigdem Koca (Turkey), Alexey Savelev (Russia), and senior members, including Ljuba Bacharova (Slovakia), Gulmira Kudaiberdieva (Turkey) and Mustafa Inan (Turkey).

The first day of ISSS began with introductions. Participants were informed about the basic schedule and how the workshops would be performed. After everybody had introduced themselves, four groups were formed. The groups included participants from different countries and different fields. Upon the formation of the groups, participants began working on their first workshop.

The first workshop was planned as an introduction to an outcome research project. The groups were expected to select the topic they would work on, explain the rationale for choosing it and to put forward a hypothesis for their research. The discussions over the first workshop, even though it seemed not to be complicated, took longer than the participants had expected, which caused some frustration among the groups because of the criticism they received. Later on, the participants expressed that this was the very first lesson they learned 


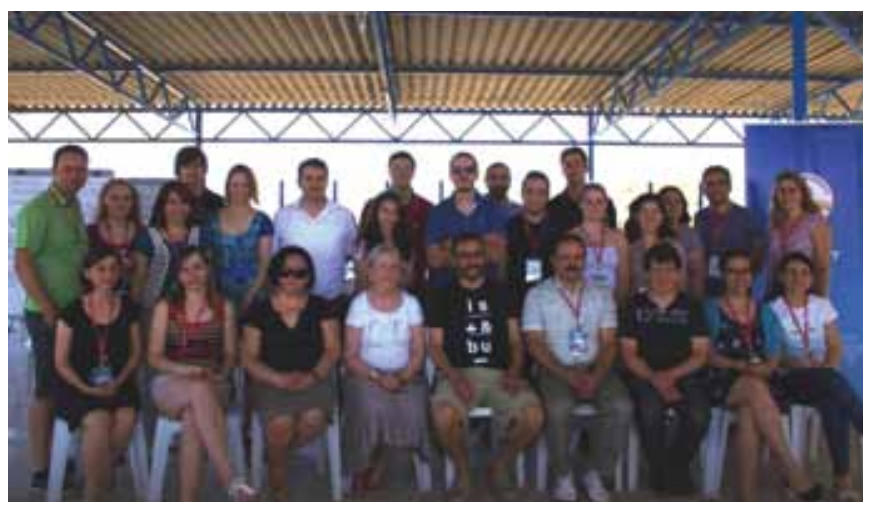

FIG. 1. The family photograph of International Scientific Summer School 2014, Enez, Turkey

from ISSS: Having questions and criticisms tends to broaden one's perspective and shed light on neglected details that in time can become obstacles of one's study. After understanding that criticism and the questions are not intended to block but to improve their study, the participants contributed to the other groups' work by asking questions.

The second workshop was about the method of the research project. The participants defined their study population and study outcomes. After working on methods, it was time for planning data collection and analysis in the third workshop. The last workshop was about planning the project's flow-chart. When the hypothesis was generated, the methods defined, the data collection and the project plans clarified, the groups made their final presentations, which reflected not only their four days' hard work on a specific research project, but also their expertise gained from those four days.

The first group of the Enez ISSS called themselves "Mosquitos" and was formed by the following individuals: Eva Blahovcova (Slovakia), Selma Korkmaz (Turkey), Ksenia Sedova (Russia), Onur Yıldırım (Turkey) and Erion Çerekja (Albania). The Mosquitos concentrated on stem cells and mtocardial infarction. They worked on the following hypothesis: "Bone marrow stem cells increase the percentage of new cardiomyocytes in the infarcted area of the heart". The hypothesis would be tested on pigs, so this was the first non-clinical experimental study design of ISSS 2014.

The group called "Noisy" was the second group formed and its members included Marina Vaykshnorayte (Russia), Erdoğan Bulut (Turkey), Zuzana Kaňková (Slovakia), Edin Demiri (Kosovo), and Serkan Balta (Turkey). The hypothesis generated by Noisy was as follows: "The combination of prenatal and postnatal noise exposure leads to differences in blood pressure and heart rate". They were interested in the relationships between noise exposure, blood pressure and heart rate. The design of the study was quite complicated as they had planned to observe the effects of various combinations of pre- and post-natal noise exposure on two generation of pigs.

The third group called themselves "Charlie's Angels" and included Enis Redjep (Macedonia) as "Charlie", and Agnieszka
Narkun (Poland), Silvia Smolarova (Slovakia), Emine Dilek (Turkey) and Sinem Bağcı (Turkey) as the angels. Charlie's Angels was the only group with a clinical study design. They had planned to test an extensive prevention program for controlling hypertension in obese children. Their hypothesis was as follows: "Intensive dietary advisement causes greater reduction in blood pressure in hypertensive children with obesity".

The fourth and final group of ISSS 2014 was called "Turtles". Turtles was formed by Sezin Fiçıcıoğlu (Turkey), Arber Gashi (Kosovo), Kıymet Tabakçıoğlu (Turkey), Maros Kolomaznik (Slovakia) and Çağatay Oltulu (Turkey). As with the former two groups, they had also chosen a non-clinical study design. In order to observe the effects of a potentially toxic drug, Turtles planned to work in the laboratory with liver cell cultures. The hypothesis generated by Turtles was as follows: "Adalimumab increases p53 and p21 levels in healthy liver cells".

ISSS in Enez was successfully completed on the fourth day with the final presentations of groups. On discussing this four-day scientific adventure, participants expressed how much they had learned about making a scientific research project in such a limited time. Most of the knowledge and expertise they gained was through learning by doing. ISSS 2014 was successfully completed with young scientists discovering the language of science, understanding the importance of team work, finding and answering the right questions, and developing their English language skills.

\section{Çiğdem KOCA, MD \\ Ankara University Faculty of Medicine}

\section{Mustafa İNAN, MD \\ Section Editor \\ Balkan Medical Journal}

\section{Cem UZUN, MD \\ Editor in Chief \\ Balkan Medical Journal}

\section{REFERENCES}

1. Bacharova L, Hakacova N. Building network for enhancement of scientific/research literacy: The Scientific Summer School 2009 in Szczepanow, Poland. Anadolu Kardiyol Derg 2009;9:433-4.

2. Kılıç D, Bacharova L. The $9^{\text {th }}$ International Scientific Summer School 2012 in Makov, Slovakia. Anadolu Kardiyol Derg 2012;12:539-41.

3. Bacharova L, Kirchnerova J. Continuous international network building to promote scientific publication: Scientific Summer School, Pezinok, Slovakia, May 25-30, 2008. Anadolu Kardiyol Derg 2008;8:319-21.

4. Inan M. Educational Perspective of the Balkan Medical Journal. Balkan Med J 2013;30:261-2. 